International Journal of Applied Linguistics \& English Literature

ISSN 2200-3592 (Print), ISSN 2200-3452 (Online)

Vol. 1 No. 4; September 2012

\title{
Burnout among Low and High Experienced Teachers
}

\author{
Seyedehhava Mousavy (Corresponding author) \\ Master student in TESL, Universiti Putra Malaysia (UPM), Serdang, Malaysia \\ Tele: (+60)169032034 E-mail:saharmsv@yahoo.com \\ Nur Sakinah Thomas \\ Master student in TESL, Universiti Putra Malaysia (UPM), Serdang, Malaysia \\ E-mail: Sakeenahthomas313@gmail.com
}

Jayakaran Mukundan

Faculty of Educational Studies, Universiti Putra Malaysia

Tel: (+60) 12-209 9717, Fax: 603-8943 5386

E-mails: jaya@educ.upm.edu.my; jayakaranmukundan@yahoo.com

Vahid Nimehchisalem

Faculty of Educational Studies, Universiti Putra Malaysia

Tel: (+60) 17-6678715 E-mails: nimechie22@yahoo.com; vahid@educ.upm.edu.my

Received: 16-06- 2012

Accepted: 07-07- 2012

Published: 01-09- 2012

doi:10.7575/ijalel.v.1n.4p.24

URL: http://dx.doi.org/10.7575/ijalel.v.1n.4p.24

\begin{abstract}
Burnout is a serious psychological syndrome that can affect not only an individual's well-being, but also the functioning of whole organisations, such as schools. It is characterized by emotional exhaustion, depersonalization, and decreased personal accomplishment. The level of burnout among teachers in the field of education has a negative impact on student success. The present investigation examines the level of burn out among high and low experienced teachers. It focused on a group of English teachers from different nationalities: Iranian, and Malaysian at UPM to examine if there is any relation between burnout and experience level. The sample consisted of 30 English teachers. Two instruments namely, The Maslach Burnout Inventory and Demographic Questionnaire were used to collect data. Data analysis revealed that there is no significant difference in depersonalization and personal accomplishment scores between low and high experienced teachers. But the result of this study also revealed that there is a significant difference in Emotional Exhaustion scores between low and high experienced teachers. Further research is required to explore the roots and the causes of burnout.
\end{abstract}

Keywords: teacher burnout, emotional exhaustion, depersonalization, personal accomplishment

\section{Introduction}

This term was first used by Graham Greene in his novel "A Burnt-out case" in 1960, in which the story of an architect was told by him who became "disappointed with his career and experienced a sense of growing loss of faith and vocation".

In psychology the term was popularised by Freudenberger (1974) he defined it as a state of physical and emotional exhaustion developing from work conditions. His definition was based on his own experience of depleted emotionality and loss of motivation.

Another pioneer of burnout research was Maslach. She based his studies on interviews with human service workers in 1976 and formulated emotional stress and its implications on job behaviour and finally came out with 
her famous Maslach Burn-out Inventory (MBI) in 1982. She proposed MBI to measure various psychological conditions like:

1. Emotional Exhaustion: feeling of over exertion and mental fatigue.

2. Depersonalization: negative attitude and isolation from co-workers.

3. Personal Accomplishment: levels of self-esteem and a sense of achievement in the work place.

It is a precise measure of teacher's psychological state with respect to their period of work and experience and is beneficial in a school system to assess the positive or negative impact on teachers themselves and on the students who are being taught by them.

The negative impact of teacher burnout on a school system can be dramatic. Reduced levels of burnout within a school system not only benefit teachers, but also students. Teachers are leaving the profession earlier and at an upper rate now than ever before. There are a lot of studies which have been done on teacher stress, anxiety and burnout. In Reglin and Reitzammer(1998) study on a group of Florida teachers indicated that if teachers could have a choice to choose a job again $30 \%$ of them wouldn't select teaching and would choose another job except to be a teacher.

Byrne (1998) found that two-thirds of new teachers will leave the job within 4 years and over half of them will leave within 7 years. DePaul (2000) found that 20-30\% of beginning teachers will leave the career in the first 3 years. All of these studies have provided evidences that stress, anxiety and/or burnout were main reasons for teachers to leave the education, many within their first 3 years in the profession and the result will be an insufficient number of trained and experienced teachers being available to staff schools. In this study there are three research objectives including:

1. To determine the difference between low experienced and high experienced teachers' Emotional

Exhaustion scores.

2. To determine the difference between low experienced and high experienced teachers' Personal Accomplishment scores.

3. To determine the difference between low experienced and high experienced teachers' Depersonalization scores.

To address the purpose of the study, three research questions were developed to guide the study:

1. What is the level of Emotional Exhaustion as indicated by respondents among low experienced and high experienced teacher?

2. What is the level of Personal Accomplishment as indicated by respondents among low experienced and high experienced teachers?

3. What is the level of Depersonalization as indicated by respondents among low experienced and high experienced teachers?

\section{Hypotheses}

The researcher aims to test the following hypotheses:

$\mathbf{H}_{\mathbf{A}}$ : There is significant difference between low experienced and high experienced teachers' Emotional Exhaustion scores.

$\mathbf{H}_{\mathbf{A} \text { : }}$ There is significant difference between low experienced and high experienced teachers' personal accomplishment scores.

$\mathbf{H}_{\mathbf{A} \text { : }}$ There is significant difference between low experienced and high experienced teachers' depersonalization scores.

\section{Literature review}

An extensive amount of research has been reported on the experience and consequences of burnout (Eastburg, Williamson, Gorsuch, \& Ridley, 1994; Pines \& Aronson, 1988). Also many studies have been done on teacher stress, anxiety and burnout and one trend is clear; teachers are leaving the profession earlier and at a upper rate now than ever before. Numerous research studies of burnout have covered the intensity of job stress, burnout, and the effect of burnout on both individuals and organizations (Brewer \& McMahan, 2003; Cheek, Bradley, Parr, \& Lan, 2003; Clarke \& Keating, 1995; Goddard, O'Brien, \& Goddard, 2006; Grayson \& Alvarez, 2008; Iwanicki \& Schwab, 1981; Kersaint, Lewis, Potter, \& Meisels, 2007; Leiter, 1991; Mattingly, 1977).The teaching profession maintains some of the maximum reported levels of burnout (Kovess-Masfety, Rios-Seidel, \& Sevilla-Dedieu, 2007; Ozdemir, 2007). Studies comparing the mental health of teachers to the mental health of 
other high-risk professionals showed a upper level of mental exhaustion in educators (Kovess-Masfety, et al., 2007; Maslach \& Leiter, 1997; Ozdemir, 2007)).The relationship between the level of burnout and teaching experience is very interesting. Many studies have been carried out in this regard.

Byrne (1998) proposed that the feeling burnout could be reduced as a result of professional maturity and that explains higher score on MBI for teachers of 0-10 years' experience compared to those having more than 10 years' experience. Konert 1997 also suggested that more experienced teachers could have developed better coping skills with their students than less experienced teachers(Duatepe \& Akkus-Cikla, 2004).

But Sunbul (2003) states that years of teaching experience and age are significantly related to burnout. Educators with more years of experience have higher levels of emotional exhaustion and depersonalization. This paradox was solved by Ozdemir 2007, who suggested that burnout appears in early and late in the career of teachers. Mid-career educators have the stamina and skills to cope up and show less burnout compared to new educators or educators of more than 24 years.

\section{Methods}

This study is quantitative in design including both descriptive and inferential statistics. The sample of the study was 30 teachers from two nationalities. They were randomly selected and were given questionnaires. The data collected for this study were analysed by using $t$ test. T-test was used to find out whether there is any significant difference between the groups in relation to their length of time in post (0-10 years and more than 10 years).

The Maslach Burnout Inventory (MBI) Educators Surveys (1986), with 22 items was used to determine the burnout level of the teachers. The questionnaire contains three subscales of emotional exhaustion, depersonalization, and personal accomplishment with nine, five and eight items respectively. The Maslach Burnout Inventory (MBI) describes burnout syndrome in terms of (a) high level of emotional exhaustion, (b) high level of depersonalization(c) reduced personal accomplishment. All items were scored on a 7-point frequency rating scale ranging from 0 "never" to 6 "daily."

The questionnaire is acceptable since the reliability scores for emotional exhaustion, depersonalization and personal accomplishment were $0.90,0.79$ and 0.71 respectively as it is reported by Maslach, Jackson and Leiter (1996).

Data were collected between April and May 2012, from volunteer students at UPM who are English teachers in Iran and Malaysia. Questionnaires were distributed in the class and the average amount of time required to complete the questionnaire was up to the respondent and there was no limitation, and the response rate was about $100 \%$. Demographic data were collected in the areas of gender, years of teaching experience, sex, educational level and status.

\section{Results and Discussion}

Spss version 18 was used to analyze the data. In this section, data analysis will be presented in tables. The participants were all English teachers from different countries. Two categories were constructed for the year of experience first the experience of 0-10 years as low experienced teachers and second the experience of more than 10 years' experience as high experienced teachers. Table 1 provides an overview of demographic data related to the gender of the respondents to the instruments. Among them, $36.7 \%$ of the participants were males and $63.3 \%$ were females. The number of male and female participated in this study is 11 and 19 in order.

Table1. Frequencies and Percentages for Gender

\begin{tabular}{ccc}
\hline gender & frequency & Percentage \\
\hline male & 11 & 36.7 \\
female) & 19 & 63.3 \\
\hline
\end{tabular}

Frequencies and percentage for years of experience are presented in Table 2, where large proportion of participants $22(73.3 \%)$ had 0 to 10 years of experience and small proportion of the participants $8(26.7 \%)$ had more than 10 years' experience.

Table2. Frequencies and Percentages for Years of Experience

\begin{tabular}{ccc}
\hline Years of experience & frequency & Percentage \\
\hline Low $(0-10)$ & 22 & 73.3 \\
High(more than 10$)$ & 8 & 26.7 \\
\hline
\end{tabular}

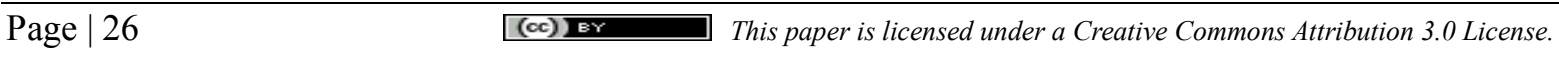


Independent samples t-test was the statistical procedure employed on the scores taken from emotional exhaustion, depersonalization and reduced personal accomplishment. Low, moderate and high are three typical levels of burnout. The study's aim was to find out whether there is significant difference between the level of burnout among low and high experienced teachers. The result of the study indicated that there is no significant difference in depersonalization and personal accomplishment scores between low and high experienced teachers. But the result of this study also revealed that there is a significant difference in Emotional Exhaustion scores between low and high experienced teachers.

The finding related to each question will be answered in order. To answer Research Question 1, what is the level of Emotional Exhaustion as indicated by respondents among low experienced and high experienced teacher? As it is shown in Table3: $\mathrm{t}(28)=-.03, \mathrm{p}>.05$. Since sig- $t(-.03)$ is smaller than $\alpha$ at .05 level of significance, the null hypothesis rejected. As a result the null hypothesis is not supported and it can be concluded that in terms of years' work-experiences, there is significant difference in Emotional Exhaustion scores between low and high experienced teachers. That is the feeling of burnout could be increased as a result of professional maturity and that explains higher score on emotional exhaustion for teachers of more than 10 years' experience compared to those having 0-10 years' experience. The Alternative hypothesis is supported in this part.

$\mathbf{H}_{01}$ : There is no significant difference between low experienced and high experienced teachers' Emotional Exhaustion scores.

Table3. Statistic and Independent Sample T-Test for Emotional Exhaustion with Reference to Experience

\begin{tabular}{ccccc}
\hline \multicolumn{5}{c}{ t-test for Equality of Means } \\
\hline $\mathrm{t}$ & $\mathrm{df}$ & $\begin{array}{c}\text { Sig. } \\
(2 \text {-tailed })\end{array}$ & $\begin{array}{c}\text { Mean } \\
\text { Difference }\end{array}$ & Std. Error Difference \\
-.031 & 28 & .975 & -.13636 & 4.33335 \\
-.040 & 21.484 & .969 & -.13636 & 3.42027 \\
\hline
\end{tabular}

To answer Research Question 2, what is the level of Personal Accomplishment as indicated by respondents among low experienced and high experienced teachers?, as it is shown in Table $4, \mathrm{t}(28)=1.404, \mathrm{p}=.17$, $\mathrm{P}>$.05.Since $\mathrm{p}(1.404)$ is greater than $\alpha$ at .05 level of significance, the null hypothesis failed to be rejected. Therefore, it can be concluded that there is no significant difference in burnout between low and high experienced teachers. The null hypothesis is supported in this part.

$\mathrm{H}_{02}$ : There is no significant difference between low experienced and high experienced teachers' personal accomplishment scores.

Table 4: Statistic and Independent Sample T-Test for Depersonalization with Reference to Experience

\begin{tabular}{ccccc}
\hline \multicolumn{5}{c}{$\mathrm{t}$-test for Equality of Means } \\
\hline $\mathrm{t}$ & $\mathrm{df}$ & $\begin{array}{c}\text { Sig. } \\
(2-\text { tailed })\end{array}$ & $\begin{array}{c}\text { Mean } \\
\text { Difference }\end{array}$ & $\begin{array}{c}\text { Std. Error } \\
\text { Difference }\end{array}$ \\
-1.404 & 28 & .171 & -3.73864 & 2.66307 \\
-1.350 & 11.632 & .203 & -3.73864 & 2.76890 \\
& & & & \\
\end{tabular}

To answer Research Question 3, what is the level of Depersonalization as indicated by respondents among low experienced and high experienced teachers?, as it is presented in Table5, $t(28)=.17, \mathrm{p}=.86, \mathrm{P}>0.05$. Since sig- $t$ (.17) is greater than $\alpha$ at .05 level of significance, the null hypothesis failed to reject. Therefore, it can be concluded that there is no significant difference in burnout between low and high experienced teachers. The null hypothesis is supported in this study.

$\mathbf{H}_{\mathbf{0 3}}$ : There is no significant difference between low experienced and high experienced teachers' depersonalization scores. 


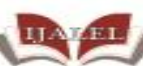

International Journal of Applied Linguistics \& English Literature

ISSN 2200-3592 (Print), ISSN 2200-3452 (Online)

Vol. 1 No. 4; September 2012

Table5. Statistic and Independent Sample T-Test for Personal Accomplishment with Reference to Experience

\begin{tabular}{ccccc}
\hline \multicolumn{5}{c}{ t-test for Equality of Means } \\
\hline $\mathrm{T}$ & $\mathrm{df}$ & $\begin{array}{c}\text { Sig. } \\
\text { (2-tailed) }\end{array}$ & $\begin{array}{c}\text { Mean } \\
\text { Difference }\end{array}$ & $\begin{array}{c}\text { Std. Error } \\
\text { Difference }\end{array}$ \\
176 & 28 & .862 & .60227 & 3.42703 \\
.210 & 18.466 & .836 & .60227 & 2.87024 \\
\hline
\end{tabular}

\section{Conclusion}

The teaching profession is claimed to be extremely demanding; therefore teachers appear to be prone to burnout. This is why the syndrome has been investigated in reference to teachers of diverse subjects or school levels. In the present study there is no significant difference between low and high experienced teachers' depersonalization scores, personal accomplishment but it explains higher score on emotional exhaustion for teachers of more than 10 years' experience compared to those having 0-10 year experience. This result is not completely consistency with previous studies.

Byrne (1998) and Konert (1997) concluded higher score on MBI for teachers of 0-10 years' experience compared to those having more than 10 years' experience. That is less experienced, higher level of burnout while Sunbul (2003) states more years of experience have higher levels of emotional exhaustion and depersonalization. Also there are some studies like Ozdemir (2007), who suggested that burnout appears in early and late in the career of teachers. Surprisingly the finding of this study is different and is contradict with other studies. There is no significant difference in depersonalization and personal accomplishment scores between low and high experienced teachers. But there is significant difference in Emotional Exhaustion scores between low and high experienced teachers. This finding was supported with the findings of Sunbul (2003) which provided evidence that years of teaching experience are significantly related to burnout. There is no literature to support the result of the study related to the personal accomplishment and depersonalization which there is no significant difference in low and high experienced teachers. The researcher confronted with limitation of time and small sample size in the present study. Most probably that is why low correlations were found between teacher burnout and experience; no statistically significant results were achieved. A larger-scale study could generate statistically significant results. It is recommended that this study could be repeated with a larger population sample in the future to get different results.

The data collection has been restricted to teachers who studying at UPM University in Malaysia. In This study the sample is confined to English teachers but the researcher did not consider them as a foreign language teacher but just a teacher in general. Since teaching a new language is different from teaching any other subject, it may require various skills thus it leads to different (most probably higher) levels of burnout. Consequently, a thorough investigation of foreign language teacher burnout should be proposed.

\section{References}

Brewer, E. W., \& McMahan, J. (2003). Job stress and burnout among industrial and technical teacher educators. Journal of Vocational Education Research, 28(2), 125-140.

Cheek, J. R., Bradley, L. J., Parr, G., \& Lan, W. (2003). Using music therapy techniques to treat teacher burnout. Journal of Mental Health Counseling, 25(3), 204-217.

Clarke, R., \& Keating, W. F. (1995). A Fresh Look at Teacher Job Satisfaction. Paper presented at the The Annual Meeting of the National Council of States on In-service Education.

DePaul, A. (2000). Survival Guide for New Teachers: How New Teachers Can Work Effectively with Veteran Teachers, Parents, Principals, and Teacher Educators. Washington D.C: US Department of Education.

Duatepe, A., \& Akkus-Cikla, O. (2004). THE RELATIONSHIP BETWEEN PRIMARY SCHOOL TEACHERSâ€тMBURNOUT AND SOME OF THEIR DEMOGRAPHIC VARIABLES. Pedagogika, 70, 55-60.

Eastburg, M. C., Williamson, M., Gorsuch, R., \& Ridley, C. (1994). Social support, personality, and burnout in nurses. Journal of Applied Social Psychology, 24(14), 1233-1250.

Freudenberger, H. J. (1974). Staff burn-out. Journal of social issues, 30(1), 159-165.

Page | $28 \quad$ This paper is licensed under a Creative Commons Attribution 3.0 License.


International Journal of Applied Linguistics \& English Literature

ISSN 2200-3592 (Print), ISSN 2200-3452 (Online)

Vol. 1 No. 4; September 2012

Goddard, R., O'Brien, P., \& Goddard, M. (2006). Work environment predictors of beginning teacher burnout. British educational research journal, 32(6), 857-874.

Grayson, J. L., \& Alvarez, H. K. (2008). School climate factors relating to teacher burnout: A mediator model. Teaching and Teacher Education, 24(5), 1349-1363.

Iwanicki, E. F., \& Schwab, R. L. (1981). A Cross Validation Study of the Maslach Burnout Inventory12. Educational and psychological measurement, 41(4), 1167-1174.

Kersaint, G., Lewis, J., Potter, R., \& Meisels, G. (2007). Why teachers leave: Factors that influence retention and resignation. Teaching and Teacher Education, 23(6), 775-794.

Kovess-Masfety, V., Rios-Seidel, C., \& Sevilla-Dedieu, C. (2007). Teachers' mental health and teaching levels. Teaching and Teacher Education, 23(7), 1177-1192.

Leiter, M. P. (1991). Coping patterns as predictors of burnout: The function of control and escapist coping patterns. Journal of Organizational behavior, 12(2), 123-144.

Maslach, C., \& Leiter, M. P. (1997). The truth about burnout. San Fransisco, Calif: Josey-Bass Publishers, 13-15.

Mattingly, M. A. (1977). Sources of stress and burn-out in professional child care work. Child and Youth Care Forum, 6(2), 127-137.

Ozdemir, Y. (2007). The role of classroom management efficacy in predicting teacher burnout. Int J Soc Sci, 2(4).

Pines, A., \& Aronson, E. (1988). Career burnout: Causes and cures: Free press.

Reglin, G., \& Reitzammer, A. (1998). Dealing with the stress of teachers. Education, 118(4).

Sunbul, A. M. (2003). An analysis of relations among locus of control, burnout and job satisfaction in Turkish high school teachers. AUSTRALIAN JOURNAL OF EDUCATION-HAWTHORN-,47(1), 58-72. 